\title{
Presenting Characteristics, Treatment Patterns, and Outcomes among Patients with Venous Thromboembolism during Hospitalization for COVID-19
}

\author{
Carmen Fernández-Capitán, MD, $\mathrm{PhD}^{1}$ Raquel Barba, MD, $\mathrm{PhD}^{2}$
}

María del Carmen Díaz-Pedroche, MD, $\mathrm{PhD}^{3}$ Patricia Sigüenza, MD, PhD ${ }^{4}$

Pablo Demelo-Rodriguez, MD, $\mathrm{PhD}^{5}$ Carmine Siniscalchi, MD, $\mathrm{PhD}^{6}$ José María Pedrajas, MD, $\mathrm{PhD}^{7}$

Ana I. Farfán-Sedano, MD ${ }^{8}$ Pavel Eduardo Olivera, $\mathrm{MD}^{9}$ Covadonga Gómez-Cuervo, MD ${ }^{10}$

Pilar Llamas, MD ${ }^{11}$ Paula Villares, MD, PhD ${ }^{12}$ Olivier Sanchez, MD, PhD ${ }^{13}$

Raquel López-Reyes, MD, PhD ${ }^{14}$ Judith Catella, MD ${ }^{15}$ Behnood Bikdeli, MD, MS 16,17,18

Ido Weinberg, MD ${ }^{19}$ Alfonso J. Tafur, MD, MS ${ }^{20}$ David Jiménez, MD, PhD21,22,23

Manuel Monreal, MD, PhD $24,25,26$ the RIETE Investigators*

${ }^{1}$ Department of Internal Medicine, Hospital Universitario La Paz, Madrid, Spain

2 Department of Internal Medicine, Hospital Rey Juan Carlos, Madrid, Spain

${ }^{3}$ Department of Internal Medicine, Hospital Universitario 12 de Octubre, Madrid, Spain

${ }^{4}$ Department of Internal Medicine, Hospital Germans Trias I Pujol, Badalona, Barcelona, Spain

${ }^{5}$ Department of Internal Medicine, Hospital General Universitario Gregorio Marañón, Madrid, Spain

${ }^{6}$ Department of Internal and Emergency Medicine, Angiology Unit, Parma University Hospital, Parma, Italy

7 Department of Internal Medicine, Hospital Clínico San Carlos, Madrid, Spain

${ }^{8}$ Department of Internal Medicine, Hospital Universitario de Fuenlabrada, Madrid, Spain

${ }^{9}$ Department of Hematology, Hospital Universitari Sagrat Cor, Barcelona, Spain

10 Department of Internal Medicine, Hospital Universitario 12 de Octubre, Madrid, Spain

11 Department of Hematology, Hospital Universitario Fundación Jiménez Díaz, Madrid, Spain

12 Department of Internal Medicine, Hospital de Madrid Norte Sanchinarro. Madrid, Spain

${ }^{13}$ Department of Pneumonology, Hôpital Europeen Georges Pompidou, Paris, France

${ }^{14}$ Department of Pneumonology, Hospital Universitari i Politècnic La Fe, Valencia, Spain

${ }^{15}$ Department of Internal Medicine, Hôpital Édouard Herriot, Lyon, France

Semin Thromb Hemost 2021;47:351-361.

\footnotetext{
* A full list of RIETE investigators is given in -Appendix 1.
}

Address for correspondence Manuel Monreal, MD, PhD, Department of Internal Medicine, Hospital Germans Trias i Pujol, Badalona, Universidad Católica de Murcia, Barcelona, 08916, Spain (e-mail: manuel.monreal@uab.cat).

\footnotetext{
${ }^{16}$ Department of Cardiology, Cardiovascular Division, Brigham and Women's Hospital, Harvard Medical School, Boston, Massachusetts

17 Department of Cardiology, Yale/YNHH Center for Outcomes Research \& Evaluation, New Haven, Connecticut

18 Department of Cardiology, Cardiovascular Research Foundation, New York, New York

${ }^{19}$ Department of Cardiology, Massachusetts General Hospital, Boston, Massachusetts

${ }^{20}$ Department of Medicine and Vascular Medicine, Evanston NorthShore University Health System, Evanston, Illinois

${ }^{21}$ Respiratory Department, Hospital Ramón y Cajal (IRYCIS), Madrid, Spain

22 Medicine Department, Universidad de Alcalá (IRYCIS), Madrid, Spain

${ }^{23}$ CIBER de Enfermedades Respiratorias (CIBERES), Madrid, Spain.

${ }^{24}$ Department of Internal Medicine, Hospital Germans Trias i Pujol, Badalona, Barcelona, Spain

${ }^{25}$ Catedra de enfermedad tromboembólica, Universidad Católica de Murcia, Spain

${ }^{26}$ CIBER de Enfermedades Respiratorias (CIBERES), Madrid, Spain
}

published online October 21, 2020
Issue Theme Maintaining Hemostasis and Preventing Thrombosis in COVID-19 -Part II; Guest Editors: Emmanuel J. Favaloro, PhD, FFSc (RCPA) and Giuseppe Lippi, MD. (c) 2020. Thieme. All rights reserved. Thieme Medical Publishers, Inc., 333 Seventh Avenue, 18th Floor, New York, NY 10001, USA
DOI https://doi.org/ 10.1055/s-0040-1718402. ISSN 0094-6176. 


\begin{abstract}
Venous thromboembolism (VTE) is common in patients with coronavirus disease-2019 (COVID-19). However, limited data exist on patient characteristics, treatments, and outcomes. To describe the clinical characteristics, treatment patterns, and short-term outcomes of patients diagnosed with VTE during hospitalization for COVID-19. This is a prospective multinational study of patients with incident VTE during the course of hospitalization for COVID-19. Data were obtained from the Registro Informatizado de la Enfermedad TromboEmbólica (RIETE) registry. All-cause mortality, VTE recurrences, and major bleeding during the first 10 days were separately investigated for patients in hospital wards versus those in intensive care units (ICUs). As of May 03, 2020, a total number of 455 patients were diagnosed with VTE (83\% pulmonary embolism, $17 \%$ isolated deep vein thrombosis) during their hospital stay; $71 \%$ were male, the median age was 65 (interquartile range, 55-74) years. Most patients (68\%) were hospitalized in medical wards, and 145 in ICUs. Three hundred and seventeen (88\%; 95\% confidence interval [CI]: 84-91\%) patients were receiving thromboprophylaxis at the time of VTE diagnosis. Most patients (88\%) received therapeutic low-molecular-weight heparin, and 15 (3.6\%) received reperfusion therapies. Among 420 patients with complete 10-day follow-up, 51 (12\%; 95\% Cl: 9.3-15\%)

Keywords

- COVID-19

- venous thromboembolism

- hospitalization

- outcomes died, no patient recurred, and $12(2.9 \% ; 95 \% \mathrm{Cl}: 1.6-4.8 \%)$ experienced major bleeding. The 10-day mortality rate was $9.1 \%$ (95\% Cl: $6.1-13 \%$ ) among patients in hospital wards and $19 \%$ (95\% Cl: 13-26\%) among those in ICUs. This study provides characteristics and early outcomes of patients diagnosed with acute VTE during hospitalization for COVID-19. Additional studies are needed to identify the optimal strategies to prevent VTE and to mitigate adverse outcomes associated.
\end{abstract}

Coagulopathy is common in patients with the novel coronavirus disease 2019 (COVID-19) and can lead to arterial and venous thromboembolic complications. ${ }^{1,2}$ Initial reports have shown a high risk of venous thromboembolism (VTE), particularly pulmonary embolism (PE) in hospitalized patients with severe COVID-19. However, a relatively small total number of patients in individual series made it unfeasible to clearly understand patient characteristics and early outcomes of these patients. $^{3-7}$ There is a paucity of information related to the presenting characteristics, use and type of VTE prophylaxis prior to thrombotic events, treatment patterns after VTE diagnosis, and outcomes of patients requiring hospitalization with COVID-19 who developed VTE during hospital admission.

The Registro Informatizado de la Enfermedad TromboEmbólica (RIETE) registry is an ongoing, multicenter, international, prospective registry of consecutive patients with symptomatic, objectively confirmed, acute VTE. ${ }^{8-10}$ Since March 25, 2020, the Steering Committee of RIETE agreed to prospectively incorporate new data elements related to patients with COVID-19. This study describes the demographics, baseline comorbidities, VTE prophylaxis patterns, initial treatment strategies, and 10-day outcomes of the first 455 patients in RIETE who were diagnosed with acute VTE during the course of hospitalization for COVID-19.

\section{Methods}

\section{Study Design}

For this study, we used the data from the RIETE registry, which prospectively collects information on patients with confirmed acute VTE (ClinicalTrials.gov identifier: NCT02832245). Previous publications have described the design and conduct of the RIETE registry. ${ }^{11}$ All patients or their health care proxies provided written or oral consent for participation in the registry in accordance with local ethics committee requirements.

The goal of this study was not to assess the comparative effectiveness of prophylactic anticoagulation before diagnosis of VTE or comparative effectives of treatment strategies after the diagnosis of VTE, but to determine the patient characteristics, treatment patterns, and outcomes, according to the routine practice across the study sites. Although RIETE currently includes patients of 222 centers from 24 countries in Asia, Europe, and the Americas, the current study only analyzed data from 56 European hospitals in Spain, France, Italy, Ireland, and Switzerland.

\section{Patient Selection}

The RIETE investigators enroll consecutive patients with objectively confirmed deep vein thrombosis (DVT) (positive lower limb venous compression ultrasonography [CUS]) or PE (typically high probability ventilation-perfusion [VQ] scintigraphy, or positive contrast-enhanced, PE-protocol, helical chest computed tomography [CT]). Only those patients who were diagnosed with acute VTE during hospitalization for COVID-19 (confirmed by positive reverse-transcription polymerase chain reaction testing in a nasopharyngeal sample) between March 25 and May 3, 2020 were included in the current manuscript. Patients diagnosed with VTE prior to hospitalization for COVID-19 
and those who developed VTE after hospital discharge were not included in this analysis.

\section{Data Elements}

Patients enrolled in RIETE had data collected from around the time of VTE diagnosis that included but were not limited to: age; gender; body weight; presence of coexisting conditions such as chronic heart or lung disease; recent $(<30$ days prior to VTE) major bleeding; presence of risk factors for PE including active cancer (defined as newly diagnosed cancer or cancer undergoing treatment [i.e., surgery, chemotherapy, radiotherapy, hormonal, or support therapy]), recent immobility (defined as nonsurgical patients assigned to bed rest with bathroom privileges for $\geq 4$ days in the 2 months prior to VTE diagnosis), surgery (defined as those who had undergone major surgery in the 2 months prior to VTE); clinical signs and symptoms on admission, including heart rate, systolic blood pressure, and arterial oxyhemoglobin saturation; use of pharmacological thromboprophylaxis; and laboratory results at hospital admission that included hemoglobin, serum creatinine, along with leukocyte, lymphocyte, and platelet counts. Since March 25, 2020, the RIETE platform added specific variables related to COVID-19 (date of diagnosis, specific blood tests, and investigational therapies for COVID-19).

\section{Outcomes}

Investigators monitored clinical outcomes until May 13, 2020, the final date of follow-up for this study. This study used all-cause mortality through 10 days after VTE diagnosis as the primary endpoint, and 10-day recurrent VTE and major bleeding as secondary endpoints. The RIETE investigators used medical record review to assess vital status. Typically, RIETE investigators defined (1) recurrent DVT as a new noncompressible vein segment, or an increase of the vein diameter by at least $4 \mathrm{~mm}$ compared with the last available measurement on venous ultrasonography; ${ }^{12}$ (2) recurrent $P E$ as a new ventilation-perfusion mismatch on lung scan or a new intraluminal filling defect on spiral CT of the chest ${ }^{13}$; and (3) major bleeding episodes as those that required a transfusion of at least 2 units of blood, were retroperitoneal, spinal, intracranial, intrathecal, intraocular, or intrapericardial, or were fatal. ${ }^{14}$

\section{Statistical Analysis}

The study reported categorical data as proportions and continuous data as mean \pm standard error or median (first-third interquartile range; IQR). We compared demographics, baseline comorbidities, presenting clinical tests, treatment patterns, and outcomes according to patients' disposition status: hospitalized in a medical ward or an intensive care unit (ICU). We used unpaired two-tailed $t$ tests or the Mann-Whitney U test (for those variables found not to follow a normal distribution) for comparisons in the distributions of continuous variables between medical ward and ICU patients, and chi-squared or Fisher's exact tests to compare the categorical data between the two groups. We used a Kaplan-Meier plot for survival data. We conducted statistical analyses with the use of SPSS (IBM SPSS Statistics for Windows, Version 25.0., IBM Corp.).

\section{Results}

We included a total of 455 hospitalized patients with COVID19 who developed VTE during hospital stay. Of these, 379 (83\%) had acute PE (with or without coexisting DVT), while 76 (17\%) had isolated DVT (i.e., without coexisting symptomatic PE) (-Fig. 1). Of the patients with PE, 351 had a positive CT scan for PE, 23 had a high-probability VQ lung scan, and five were diagnosed through a pulmonary angiogram. All DVTs were documented by CUS. At the time of VTE diagnosis, most patients ( $n=310$; 68\%; 95\% confidence interval [CI]: 64-72\%) were hospitalized in medical wards, and 145 in ICUs.

- Table 1 summarizes the baseline characteristics. Overall, the median age was 65 years (IQR: 55-74; range: 25-99 years), and $71 \%$ were male. The most common comorbidities were hypertension $(190 ; 42 \%)$, diabetes (93; 20\%), and chronic lung disease (including asthma, chronic obstructive pulmonary disease, fibrosis, and bronchiectasis) (44; 9.7\%). Most patients (78\%) had recent immobilization, $4.4 \%$ had active cancer, and $18 \%$ had no identifiable risk factor other than acute COVID-19. Patients with VTE who were admitted to the ICU were younger ( $61 \pm 12$ vs. $65 \pm 14$ years; $p=0.011$ ), were more likely to be men ( 81 vs. $67 \%$; absolute difference $[\mathrm{AD}]: 14 \%$; $95 \% \mathrm{CI}: 5.2-22 \%$ ), and current smokers (8.3 vs. $2.6 \%$; $A D$ : $5.7 \%$; $95 \%$ CI: $1.5-12 \%$ ), but less likely to have acute PE (76 vs. $87 \%$; $\mathrm{AD}$ : $11 \%$; $95 \% \mathrm{CI}: 3.4-19 \%$ ), compared with those who were admitted to the ward. Anemia (74 vs. 46\%; AD: 28\%; 95\% CI: 19-37\%), neutrophilia (53 vs. 34\%; AD: 19\%; 95\% CI: 8.9-29\%), lymphopenia (51 vs. 42\%; AD: 9.3\%; 95\% CI: 1.2-20\%), and abnormal prothrombin time (36 vs. $23 \%$; AD: $13 \%$; $95 \% \mathrm{CI}: 3.0-22 \%$ ) were more common in patients who were admitted to the ICU.

Information on the use of VTE prophylaxis prior to index VTE events was available in 360 (79\%) patients. At the time of VTE diagnosis, 317 (88\%) patients were receiving pharmacological prophylaxis: 203 (64\%) were receiving standard-dose low-molecular-weight heparin (LMWH; e.g., enoxaparin $40 \mathrm{mg}$ once daily [od], dalteparin 5,000 IU od), 79 (25\%) had received intermediate-dose $\mathrm{LMWH}$, and 24 (7.8\%) had received therapeutic-dose LMWH (e.g., enoxaparin 1.5$\mathrm{mg} / \mathrm{kg}$ od) (-Table 1). The median duration of prophylaxis prior to VTE diagnosis was 10 days (IQR: 6-15 days) (-Fig. 2). Of the patients who were admitted to the ICU, $96 \%$ were receiving pharmacological thromboprophylaxis, compared with $84 \%$ of those who were admitted to the ward (AD: $12 \%$; 95\% CI: 5.3-18\%).

\section{VTE Presentation and Initial Treatment}

The median time from admission for COVID-19 to VTE diagnosis was 10 days (IQR: 5-16 days), and the median time from VTE to discharge was 9 days (IQR: 5-14 days). - Table 2 describes the patients' features at the time of VTE diagnosis. Among 379 patients with PE, 18\% were tachycardic (heart rate $>110 / \mathrm{min}$ ) and $20 \%$ had a systolic 


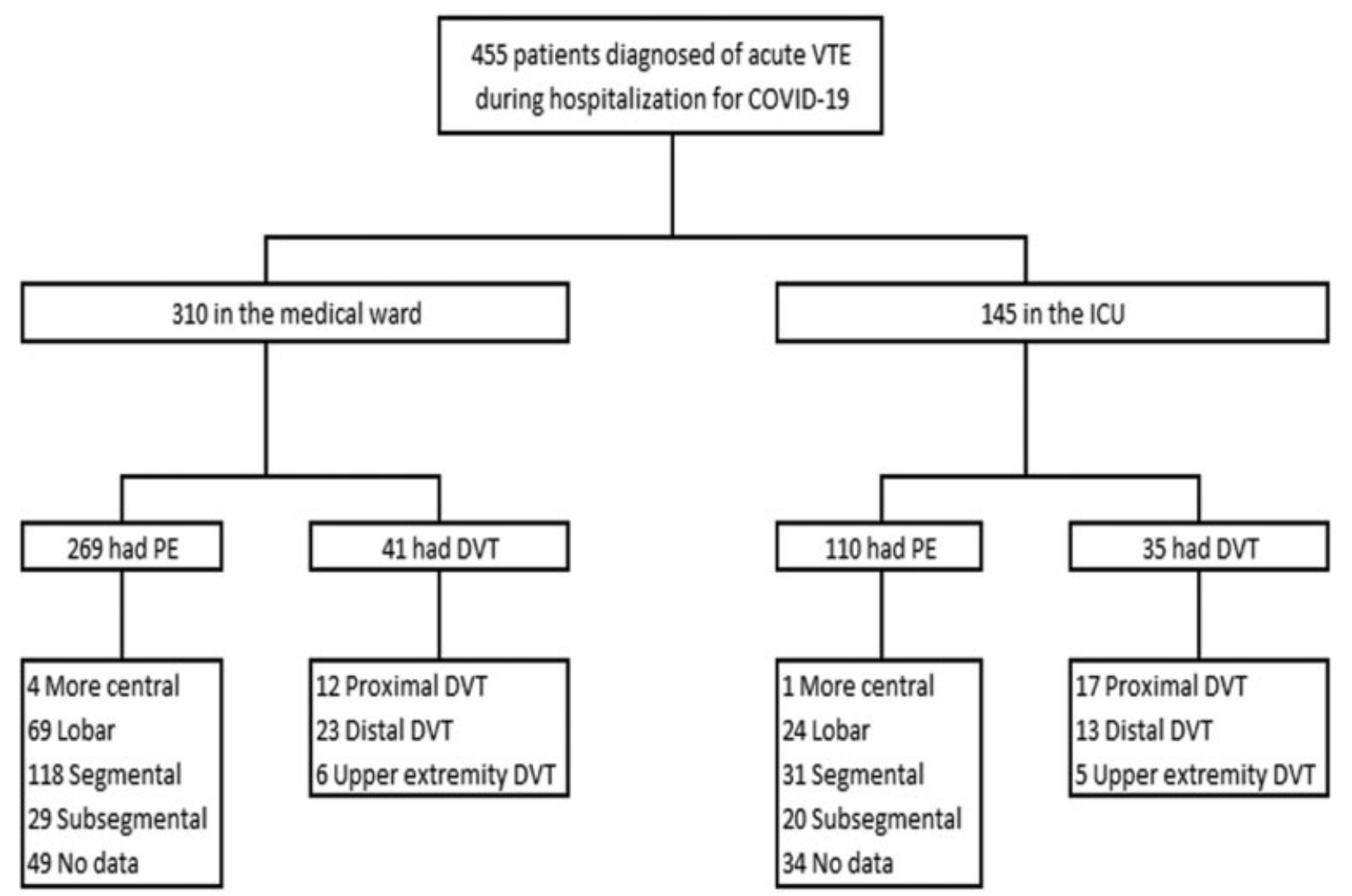

Fig. 1 Study flow chart. COVID-19, coronavirus disease-2019; DVT, deep vein thrombosis; ICU, intensive care unit; PE, pulmonary embolism; VTE, venous thromboembolism.

blood pressure $<100 \mathrm{~mm} \mathrm{Hg}$ or were using vasopressors. Sixty-seven percent of patients had PEs limited to segmental and/or subsegmental arteries. Echocardiographic data were obtained in 97 patients; $36 \%$ had pulmonary artery pressure levels $>40 \mathrm{~mm} \mathrm{Hg}, 17 \%$ had tricuspid annular plane systolic excursion (TAPSE) $\leq 16 \mathrm{~mm}$, and $33 \%$ had right ventricular dysfunction. In patients with PE, those in the ICU were more likely to have hypotension (i.e., systolic blood pressure $<100 \mathrm{~mm} \mathrm{Hg}$ or using vasopressors) (49 vs. 9.7\%; AD: $40 \%$; $95 \% \mathrm{CI}: 30-49 \%$ ) or tachycardia (28 vs. $15 \%$; AD: $13 \%$; 95\% CI: 4.2-23\%).

After the diagnosis of acute symptomatic VTE, 99.8\% of patients (all but one) were started on full-dose anticoagulation. Most patients $(367 ; 88 \%)$ received weight-adjusted LMWH, while 27 (6.4\%) received unfractionated heparin (UFH). Overall, 15 (3.6\%) patients received reperfusion therapies (thrombolysis: 11; percutaneous thrombectomy: 1 , surgical thrombectomy: 3), 6 underwent extracorporeal membrane oxygenation (ECMO), and an inferior vena cava filter was inserted in 8 (1.9\%). Patients admitted to an ICU were more likely to receive UFH, thrombolytic therapy, vasopressors, or ECMO than those admitted to the medical ward (-Table 3 ).

\section{Outcomes}

Outcomes were available in 420 patients who had completed the 10 days follow-up or had died by the end of day 10 . Fiftyone patients (12\%; $95 \% \mathrm{CI}$ : 9.3-15\%) died, 12 patients $(2.9 \%$; 95\% CI: 1.6-4.8\%) experienced a major bleeding event (retro- peritoneal 4, intracranial 3 , gastrointestinal 3 , urinary 1 , hematoma 1$)$, and none (0\%; $95 \% \mathrm{CI}$ : $0-1.0 \%)$ had recurrent VTE (- Table 4).

For patients who were discharged alive, the overall median time from COVID-19 diagnosis to hospital discharge was 20 (IQR: 15-25) days. The median number of days from VTE diagnosis to hospital discharge in these patients was 9 (IQR: 5-14) days. The percentage of patients who died was higher among those patients older than 70 years (-Fig. 3). Among patients with PE, 45 (13\%; 95\% CI: 9.7-17\%) died, compared with 6 (8.3\%; 95\% CI: 3.4-17\%) among those with DVT (AD: 3.3\%; $95 \% \mathrm{CI}$ : $-7.3-10 \%)$. Only one of the 72 patients initially presenting with isolated DVT bled. Patients admitted to the ICU had significantly higher rates of all-cause mortality (19 vs. 9.1\%; AD: 9.6\%; 95\% CI: 2.6-19\%) and major bleeding (6.7 vs. $0.9 \%$; AD: $5.7 \%$; $95 \%$ CI: $2.0-12 \%$ ) than those admitted to the ward (-Fig. 4).

\section{Discussion}

This study represents a large multinational series of hospitalized patients with COVID-19 who developed VTE during hospital admission. Among these patients, nearly $75 \%$ were men over 60 years of age and mostly presented with acute PE. Eighty-eight percent were receiving pharmacological thromboprophylaxis at the time of VTE diagnosis and 12\% died during the first 10 days after diagnosis and initiation of therapy.

The population of patients in this study consisted mostly of aged men and comorbidities were similar to those 
Table 1 Baseline characteristics and use of pharmacological prophylaxis, according to patients' disposition status

\begin{tabular}{|c|c|c|c|c|}
\hline & All & Ward & $\begin{array}{l}\text { Intensive } \\
\text { care unit }\end{array}$ & $\begin{array}{l}\text { Difference } \\
(95 \% \mathrm{Cl})\end{array}$ \\
\hline Patients, $N$ & 455 & 310 & 145 & \\
\hline \multicolumn{5}{|l|}{ Clinical characteristics } \\
\hline Male gender & $324(71 \%)$ & $207(67 \%)$ & $117(81 \%)$ & $14(5.0-23)$ \\
\hline Age, y (mean \pm SD) & $64 \pm 14$ & $65 \pm 14$ & $61 \pm 12$ & $3.5(0.8-6.1)$ \\
\hline Body weight, kg (mean $\pm S D)$ & $80 \pm 16$ & $78 \pm 14$ & $85 \pm 18$ & $6.8(3.6-10)$ \\
\hline \multicolumn{5}{|l|}{ Initial VTE presentation } \\
\hline Isolated PE & $316(69 \%)$ & $231(75 \%)$ & 85 (59\%) & $15.9(6.89-24.9)$ \\
\hline PE and DVT concomitantly & $63(14 \%)$ & $38(12 \%)$ & $25(17 \%)$ & $4.98(1.85-11.8)$ \\
\hline Isolated DVT & $76(17 \%)$ & $41(13 \%)$ & $35(24 \%)$ & $10.9(3.59-18.2)$ \\
\hline \multicolumn{5}{|l|}{ Concomitant disorders } \\
\hline Chronic lung disease & $44(9.7 \%)$ & $33(11 \%)$ & $11(7.6 \%)$ & $3.1(-2.8-8.9)$ \\
\hline Recent ( $<30 \mathrm{~d}$ ) major bleeding & $13(2.9 \%)$ & $10(3.2 \%)$ & $3(2.1 \%)$ & $1.2(-2.1-4.5)$ \\
\hline Diabetes & $93(20 \%)$ & $57(18 \%)$ & $36(25 \%)$ & $6.4(1.5-14)$ \\
\hline Arterial hypertension & $190(42 \%)$ & $125(40 \%)$ & $65(45 \%)$ & $4.5(5.3-14)$ \\
\hline Current smoking & $20(4.4 \%)$ & $8(2.6 \%)$ & $12(8.3 \%)$ & $5.7(1.7-9.7)$ \\
\hline Coronary heart disease & $26(5.7 \%)$ & $19(6.1 \%)$ & $7(4.8 \%)$ & $1.3(-3.3-5.9)$ \\
\hline \multicolumn{5}{|l|}{ Risk factors for VTE } \\
\hline Recent immobility & $354(78 \%)$ & $233(75 \%)$ & $121(83 \%)$ & $8.3(0.1-17)$ \\
\hline Recent surgery & $9(2.0 \%)$ & $7(2.3 \%)$ & $2(1.4 \%)$ & $0.9(-1.9-3.6)$ \\
\hline Active cancer & $20(4.4 \%)$ & $17(5.5 \%)$ & $3(2.1 \%)$ & $3.4(-0.6-7.5)$ \\
\hline Estrogen use & $6(1.3 \%)$ & $5(1.6 \%)$ & $1(0.7 \%)$ & $0.9(-1.3-3.2)$ \\
\hline Pregnancy/postpartum & $1(0.2 \%)$ & $1(0.3 \%)$ & 0 & $0.3(-0.6-1.3)$ \\
\hline History of VTE & $17(3.8 \%)$ & $14(4.5 \%)$ & $3(2.1 \%)$ & $2.4(-1.4-6.2)$ \\
\hline None of the above & $84(18 \%)$ & $62(20 \%)$ & $22(15 \%)$ & $4.8(-2.9-13)$ \\
\hline \multicolumn{5}{|l|}{ Laboratory findings } \\
\hline Anemia & $251(55 \%)$ & $143(46 \%)$ & $108(74 \%)$ & $28(19-38)$ \\
\hline Leukocytosis (> $11 \times 109 /$ L) & $161(36 \%)$ & $95(31 \%)$ & $66(46 \%)$ & $16(6.2-25)$ \\
\hline Neutropenia $(<8 \times 109 /$ L) & $166(40 \%)$ & $96(34 \%)$ & $70(53 \%)$ & $19(9.0-29)$ \\
\hline Lymphopenia $(<1.0 \times 109 / L)$ & $177(45 \%)$ & $113(42 \%)$ & $64(51 \%)$ & $9.4(1.2-20)$ \\
\hline Thrombocytopenia $(<100 \times 109 / \mathrm{L})$ & $8(1.8 \%)$ & $5(1.6 \%)$ & $3(2.1 \%)$ & $0.5(2.2-3.2)$ \\
\hline Elevated D-dimer (> $10.0 \mathrm{mcg} / \mathrm{mL})$ & $74(23 \%)$ & $52(23 \%)$ & $22(22 \%)$ & $1.2(-8.7-11)$ \\
\hline Prolonged PT $($ INR > 1.2) $(N=397)$ & $108(27 \%)$ & $64(23 \%)$ & $44(36 \%)$ & $12(3.0-22)$ \\
\hline $\mathrm{CrCl}$ levels $(<60 \mathrm{~mL} / \mathrm{min})$ & $80(18 \%)$ & $49(16 \%)$ & $31(21 \%)$ & $5.6(2.0-13)$ \\
\hline VTE prophylaxis $(N=360)$ & 360 & 238 & 122 & \\
\hline Yes & $317(88 \%)$ & $200(84 \%)$ & $117(96 \%)$ & $12(4.9-19)$ \\
\hline Duration, d (median, IQR) & $10(6-15)$ & $10(6-15)$ & $10(6-16)$ & $0.7(-1.4-2.9)$ \\
\hline Standard LMWH doses & $203(64 \%)$ & $135(67 \%)$ & $68(56 \%)$ & $9.4(1.5-20)$ \\
\hline Intermediate LMWH doses & $79(25 \%)$ & $41(21 \%)$ & $38(32 \%)$ & $12(2.1-22)$ \\
\hline Full therapeutic LMWH doses & $24(7.8 \%)$ & $14(7.0 \%)$ & $10(8.2 \%)$ & $1.6(4.3-8.6)$ \\
\hline Other anticoagulants & $11(3.5 \%)$ & $10(5.0 \%)$ & $1(0.8 \%)$ & $4.2(0.3-8.2)$ \\
\hline
\end{tabular}

Abbreviations: $\mathrm{Cl}$, confidence interval; $\mathrm{CrCl}$, creatinine clearance; DVT, deep vein thrombosis; IQR, interquartile range; LMWH, low-molecular-weight heparin; PE, pulmonary embolism; PT, prothrombin time; SD, standard deviation; VTE, venous thromboembolism. 

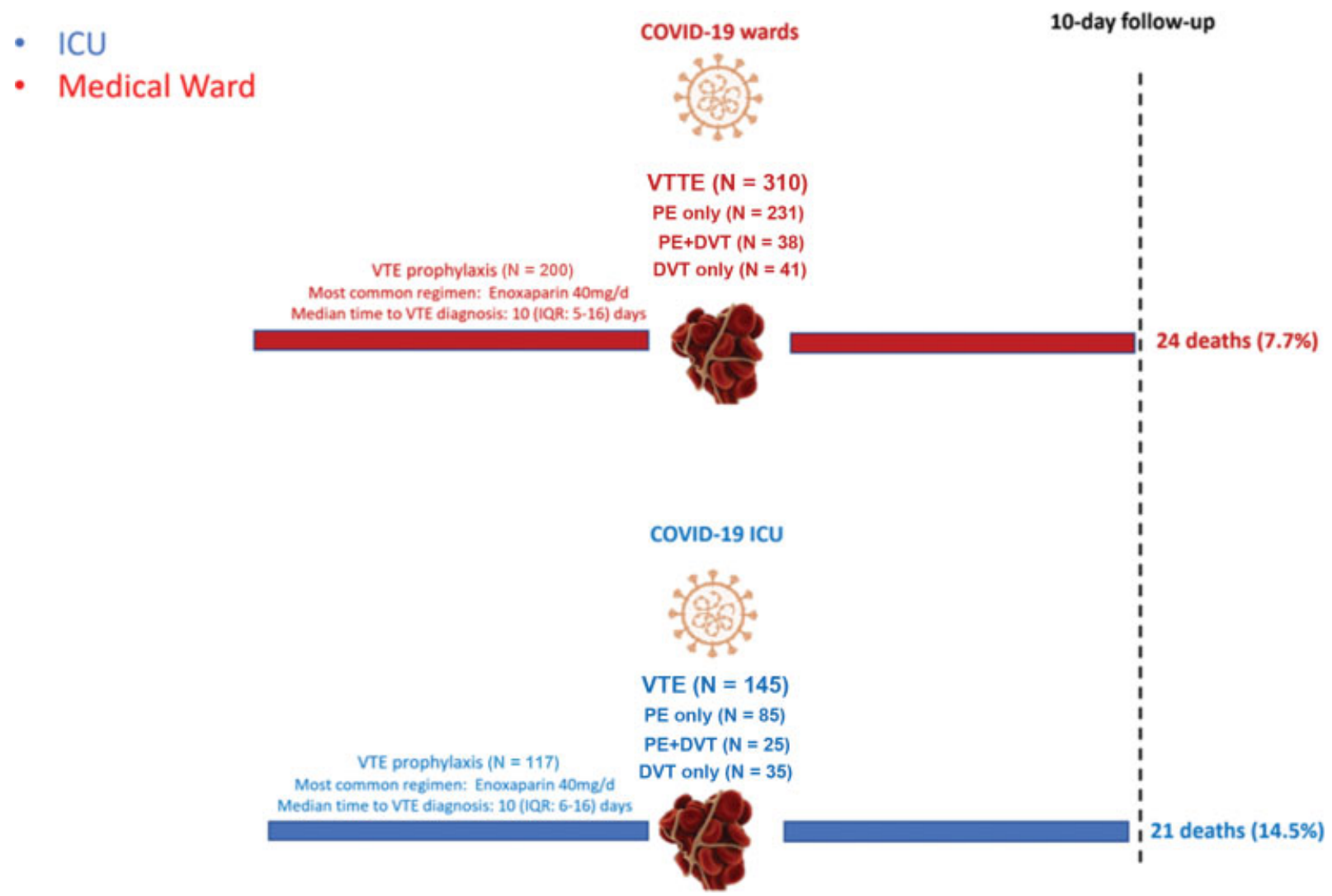

Fig. 2 Graphical representation of use of VTE prophylaxis, timing of diagnosis, and 10-day outcomes. COVID-19: coronavirus disease 2019; DVT: deep vein thrombosis; ICU: intensive care unit; PE: pulmonary embolism; VTE: venous thromboembolism

reported in other studies. ${ }^{14-17}$ Besides COVID-19 itself, immobilization was the most frequent predisposing risk factor for acute VTE among these patients. ${ }^{18}$ In this study, $32 \%$ VTE events were noted during the ICU stay. Although a direct breakdown of VTE in ICUs versus medical wards is not yet available from other large VTE series, prior studies of patients hospitalized with COVID-19 have reported variable rates of VTE, with higher incidence rates in the ICU. ${ }^{13,19,20}$

In our study, pharmacological thromboprophylaxis was used systematically among most patients with COVID-19 prior to the development of VTE. Further, one-third of these patients received higher than usual prophylactic doses. Among patients hospitalized for COVID-19, some of the existing studies have indicated an unusually high incidence of VTE, despite the use of VTE prophylaxis. ${ }^{3,21}$ A study from the Netherlands included 198 patients with COVID-19, 74 (37\%) of whom were in the ICU. ${ }^{6}$ Standard or substandard LMWH was routinely used for VTE prophylaxis for study participants. After a median observation time of 5 days, 33 patients (17\%) were diagnosed with PE or DVT. In our study, the fact that $88 \%$ of patients with VTE had received prophylactic anticoagulation suggests that COVID-19 may be a prothrombotic disease and that standard prophylactic dosing may not suffice to overcome the prothrombotic milieu. However, the optimal regimen in the prevention of VTE in COVID-19 remains unknown. Findings from several ongoing randomized trials will be informative in the near future (NCT04345848, NCT04344756, NCT04359277, NCT04362085, NCT04367831, NCT04377997, NCT04394377, and NCT04373707).
In accordance with previous studies, more than twothirds of patients in our series presented with PE, and 67\% of them involved isolated to distal (segmental and subsegmental) branches of pulmonary arteries, often without concurrent DVT. ${ }^{21,22}$ Therefore, some authors have hypothesized that the observed pulmonary artery occlusions could be local pulmonary thrombi in the setting of inflammatory response (immunothrombosis), rather than an embolic phenomenon. ${ }^{23-25}$ This observation is compatible with some postmortem descriptions of thrombotic microangiopathy, ${ }^{26}$ which is also observed in other organs. Whether intervening earlier with anticoagulants before patients develop acute respiratory distress syndrome would make a difference or whether preventing the microvascular thrombosis will change outcomes remains to be determined.

All-cause mortality rates in this cohort were significantly lower than those reported from China, ${ }^{27}$ but similar to others in the United States. ${ }^{14,17}$ The exact reasons behind these differences are unknown, but they may be related to regional differences in testing strategies, variable threshold for decision to hospitalize patients, and regional differences in therapies offered for the management of COVID-19 and its complications. Another reason could be that we only studied 10-day mortality, whereas reports of in-hospital mortality from other studies may have spanned a longer median period of time. In this regard, future longer term follow-up data from our cohort will almost certainly indicate a higher case fatality rate. The death rate was higher among those who were older. The findings of higher mortality rates among ICU 
Table 2 Clinical signs (A) and imaging test results (B)

\begin{tabular}{|c|c|c|c|c|}
\hline & All patients & Ward & $\begin{array}{l}\text { Intensive } \\
\text { care unit }\end{array}$ & $\begin{array}{l}\text { Difference } \\
(95 \% \mathrm{Cl})\end{array}$ \\
\hline \multicolumn{5}{|l|}{ A. Clinical signs } \\
\hline Pulmonary embolism, $N$ & 379 & 269 & 110 & \\
\hline \multicolumn{5}{|l|}{ Vital signs } \\
\hline SBP levels $<90 \mathrm{~mm} \mathrm{Hg}$ & 16 (4.4\%) & $7(2.6 \%)$ & $9(9.4 \%)$ & $6.7(2.0-12)$ \\
\hline SBP levels $<100 \mathrm{~mm} \mathrm{Hg}$ & 40 (11\%) & $19(7.2 \%)$ & $21(22 \%)$ & $14.7(7.49-21.9)$ \\
\hline SBP levels $<100 \mathrm{~mm} \mathrm{Hg}$ or vasopressors & $55(20 \%)$ & $20(9.7 \%)$ & $35(49 \%)$ & $39.6(29.8-49.4)$ \\
\hline Sat $\mathrm{O}_{2}$ levels, \% (mean $\left.\pm \mathrm{SD}\right)$ & $92 \pm 7.4$ & $92 \pm 8.3$ & $92 \pm 5.3$ & $0.8(1.5-3.2)$ \\
\hline Sat $\mathrm{O}_{2}$ levels $<90 \%$ & $40(24 \%)$ & $29(26 \%)$ & $11(19 \%)$ & $6.59(-7.10-20.3)$ \\
\hline Heart rate, bpm (mean \pm SD) & $91 \pm 21$ & $89 \pm 18$ & $97 \pm 27$ & $8.3(3.3-13)$ \\
\hline Heart rate $>110 /$ min & $62(18 \%)$ & $37(15 \%)$ & $25(28 \%)$ & $13.5(4.21-22.7)$ \\
\hline \multicolumn{5}{|l|}{ B. Imaging test results } \\
\hline Echocardiography, $N$ & 97 & 56 & 41 & \\
\hline PAP levels, $\mathrm{mm} \mathrm{Hg}($ mean \pm SD) & $40 \pm 13$ & $37 \pm 9.8$ & $45 \pm 16$ & $7.5(2.5-18)$ \\
\hline Right ventricle hypokinesis & $27(33 \%)$ & $10(21 \%)$ & $17(50 \%)$ & $29(8.3-49)$ \\
\hline TAPSE, mm (mean \pm SD) & $20 \pm 4.9$ & $22 \pm 4.4$ & $17 \pm 4.8$ & $4.4(1.4-7.3)$ \\
\hline TAPSE $\leq 16 \mathrm{~mm}$ & $8(17 \%)$ & $3(9.4 \%)$ & $5(36 \%)$ & $26(2.63-50)$ \\
\hline Burden of PE on CT scan, $N$ & 296 & 220 & 76 & \\
\hline Main & $5(1.7 \%)$ & $4(1.8 \%)$ & $1(1.3 \%)$ & $0.5(-2.9-3.9)$ \\
\hline Lobar & $93(31 \%)$ & $69(31 \%)$ & $24(32 \%)$ & $0.2(-11-13)$ \\
\hline Segmental & $149(50 \%)$ & $118(54 \%)$ & $31(41 \%)$ & $13(-0.2-26)$ \\
\hline Subsegmental & $49(17 \%)$ & $29(13 \%)$ & $20(26 \%)$ & $13(3.5-23)$ \\
\hline Lower limb ultrasound testing & 47 & 25 & 22 & \\
\hline Concomitant DVT & $19(40 \%)$ & $7(28 \%)$ & $12(55 \%)$ & $27(1.9-55)$ \\
\hline Deep vein thrombosis, $N$ & 76 & 41 & 35 & \\
\hline Proximal DVT, lower limb & $29(38 \%)$ & $8(19 \%)$ & $17(49 \%)$ & $29(8.3-50)$ \\
\hline Distal DVT, lower limb & $36(47 \%)$ & $23(56 \%)$ & $13(37 \%)$ & $19(-3.8-42)$ \\
\hline Upper extremity DVT & $11(14 \%)$ & $6(15 \%)$ & $5(14 \%)$ & $0.4(-16-17)$ \\
\hline
\end{tabular}

Abbreviations: CT, computed tomography; DVT, deep vein thrombosis; IQR, interquartile range; PAP, pulmonary artery pressure; PE, pulmonary embolism; SBP, systolic blood pressure; SD, standard deviation; TAPSE, tricuspid annular plane systolic excursion; VTE, venous thromboembolism.

patients are similar to other limited case series reports of critically ill patients in the United States. ${ }^{27,28}$ No recurrences were reported in the first 10 days after diagnosis of VTE and initiation of therapy. This may have been due to the short period of time from diagnosis to the end of the study, possible lack of enthusiasm from treating practitioners to retest for VTE, or truly a lower event rate for recurrence in patients with COVID-19. PE is difficult to recognize in hospitalized COVID-19 patients, particularly in those who are critically ill. ${ }^{6}$

This study has several limitations. First, since the RIETE registry only enrolls patients with confirmed VTE, we could not evaluate the incidence of VTE in patients who were hospitalized for COVID-19. In the absence of systematic screening or a standardized protocol for testing, patient characteristics and outcomes may have been influenced by discretionary decisions to test and diagnose VTE. Also, emerging data indicate incidentally discovered, otherwise unsuspected, PE in postmortem studies of patients with COVID-19, including cases in which PE was the cause of death. ${ }^{25,29}$ However, despite this limitation, our sites included both large referral hospitals and smaller communitybased hospitals in several countries, and reflect VTE diagnosis in routine practice, as well as treatment patterns and patient outcomes. A second limitation is that in the absence of an independent adjudication committee or autopsy, this study cannot provide information on the specific contribution of VTE to the mortality rate that we observed among patients who required hospitalization for COVID-19. Third, subgroup descriptive statistics were unadjusted for potential confounders. The goal of this study was not to identify the predictors of mortality in patients with COVID-19, including patients with COVID-19 who developed incident VTE. Rather, we attempted to describe the patient characteristics, preVTE prophylaxis pattern, treatment pattern, and short-term outcomes in a large series of patients with COVID-19 who 
Table 3 Initial management of patients diagnosed with acute VTE during hospitalization for COVID-19 (data were only available for 420 patients)

\begin{tabular}{|c|c|c|c|c|}
\hline & All patients & Ward & $\begin{array}{l}\text { Intensive } \\
\text { care unit }\end{array}$ & $\begin{array}{l}\text { Difference } \\
(95 \% \mathrm{Cl})\end{array}$ \\
\hline Patients, $N$ & 420 & 286 & 134 & \\
\hline Low-molecular-weight heparin & 367 (88\%) & 267 (93\%) & $100(75 \%)$ & $19(12-25)$ \\
\hline Unfractionated heparin & $27(6.4 \%)$ & $4(1.4 \%)$ & $23(17 \%)$ & $16(11-21)$ \\
\hline Fondaparinux & $6(1.4 \%)$ & $6(2.1 \%)$ & 0 & $2.1(-0.4-4.6)$ \\
\hline Direct oral anticoagulants & $8(1.9 \%)$ & $8(2.8 \%)$ & 0 & $2.8(-0.02-5.6)$ \\
\hline Systemic thrombolysis & $11(2.6 \%)$ & $1(0.4 \%)$ & $10(7.5 \%)$ & $7.2(3.9-10)$ \\
\hline Percutaneous embolectomy & $1(0.3 \%)$ & 0 & $1(0.9 \%)$ & $0.9(0.4-2.2)$ \\
\hline Surgical embolectomy & $3(0.7 \%)$ & $2(0.7 \%)$ & $1(0.8 \%)$ & $0.1(-1.9-1.8)$ \\
\hline Inferior vena cava filter & $8(1.9 \%)$ & $3(1.1 \%)$ & $5(3.8 \%)$ & $2.8(0.1-5.7)$ \\
\hline Use of vasopressors & $38(12 \%)$ & $3(1.4 \%)$ & 35 (33\%) & $31(25-38)$ \\
\hline ECMO & $6(1.8 \%)$ & 0 & $6(5.6 \%)$ & $5.6(2.5-8.6)$ \\
\hline
\end{tabular}

Abbreviations: $\mathrm{Cl}$, confidence intervals; ECMO, extracorporeal membrane oxygenation; VTE, venous thromboembolism.

Table 4 Outcomes among 420 patients diagnosed with acute VTE during hospitalization for COVID-19, according to initial VTE presentation

\begin{tabular}{|c|c|c|c|c|}
\hline & All patients & Ward & $\begin{array}{l}\text { Intensive } \\
\text { care unit }\end{array}$ & $\begin{array}{l}\text { Difference } \\
(95 \% \mathrm{Cl})\end{array}$ \\
\hline Pulmonary embolism, $N$ & 348 & 247 & 101 & \\
\hline VTE recurrences & 0 & 0 & 0 & - \\
\hline Major bleeding & $11(3.2 \%)$ & $3(1.2 \%)$ & $8(7.9 \%)$ & $6.7(2.7-11)$ \\
\hline Retroperitoneal & $4(1.1 \%)$ & $1(0.4 \%)$ & $3(3.0 \%)$ & $2.6(0.1-5.0)$ \\
\hline Intracranial & $3(0.9 \%)$ & $1(0.4 \%)$ & $2(2.0 \%)$ & $1.6(0.6-3.7)$ \\
\hline Gastrointestinal & $2(0.6 \%)$ & 0 & $2(2.0 \%)$ & $2.0(0.2-3.7)$ \\
\hline Urinary & $1(0.3 \%)$ & $1(0.4 \%)$ & 0 & $0.4(-0.8-1.7)$ \\
\hline Hematoma & $1(0.3 \%)$ & 0 & $1(1.0 \%)$ & $1.0(0.3-2.2)$ \\
\hline Death & $45(13 \%)$ & $22(8.9 \%)$ & $23(23 \%)$ & $14(6.2-22)$ \\
\hline Fatal PE & $8(2.3 \%)$ & $3(1.2 \%)$ & $5(5.0 \%)$ & $3.7(0.3-7.2)$ \\
\hline Fatal bleeding & $1(0.3 \%)$ & 0 & $1(1.0 \%)$ & $1.0(0.3-2.2)$ \\
\hline Sudden, unexpected & $4(1.1 \%)$ & $2(0.8 \%)$ & $2(2.0 \%)$ & $1.2(-3.7-1.3)$ \\
\hline Deep vein thrombosis, $N$ & 72 & 39 & 33 & \\
\hline VTE recurrences & 0 & 0 & 0 & - \\
\hline Major bleeding & $1(1.4 \%)$ & 0 & $1(3.0 \%)$ & $3.0(2.5-8.6)$ \\
\hline Death & $6(8.3 \%)$ & $4(10 \%)$ & $2(6.1 \%)$ & $4.2(-9.0-17)$ \\
\hline Fatal PE & 0 & 0 & 0 & - \\
\hline Fatal bleeding & 0 & 0 & 0 & - \\
\hline Sudden, unexpected & 0 & 0 & 0 & - \\
\hline
\end{tabular}

Abbreviations: $\mathrm{Cl}$, confidence intervals; PE, pulmonary embolism; VTE, venous thromboembolism.

developed VTE. Separate studies are required to better understand the magnitude of risk from VTE in patients with COVID-19. Among patients with COVID-19 who develop incident VTE, a separate RIETE investigation is being planned -once a larger number of patients and longer follow-up are accrued-to identify the predictors of all-cause mortality in multivariable analysis. Finally, as stated earlier, it must be clarified that the current study did not focus on the comparative effectiveness of strategies for VTE prevention or treatment. Results from ongoing randomized trials will be most informative for that purpose. ${ }^{30}$

In conclusion, this study provides characteristics and early outcomes of patients diagnosed with acute VTE during hospitalization for COVID-19. Additional studies are needed 
VTE in Patients Hospitalized for COVID-19 Fernández-Capitán et al. 359

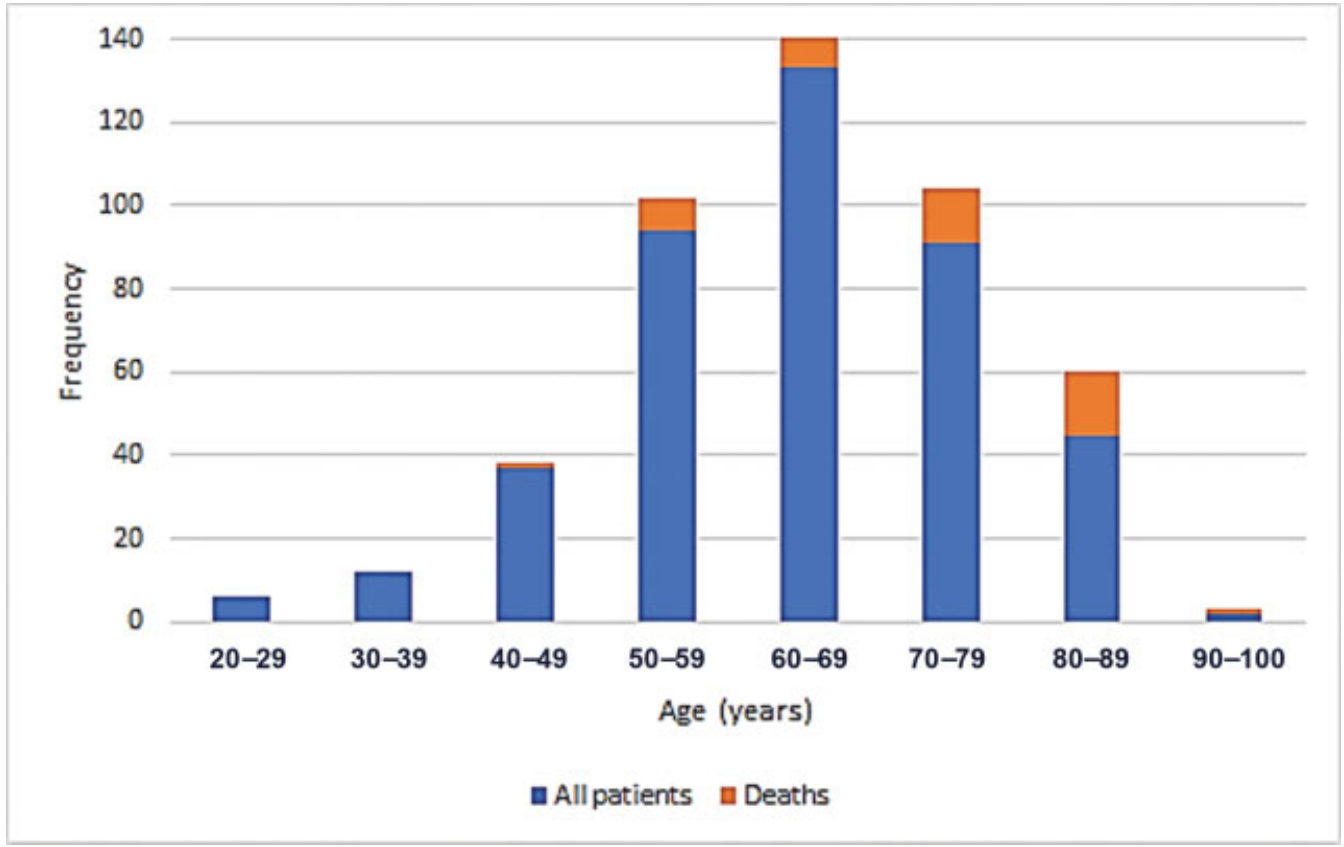

Fig. 3 Survival status by 10 -year age intervals.

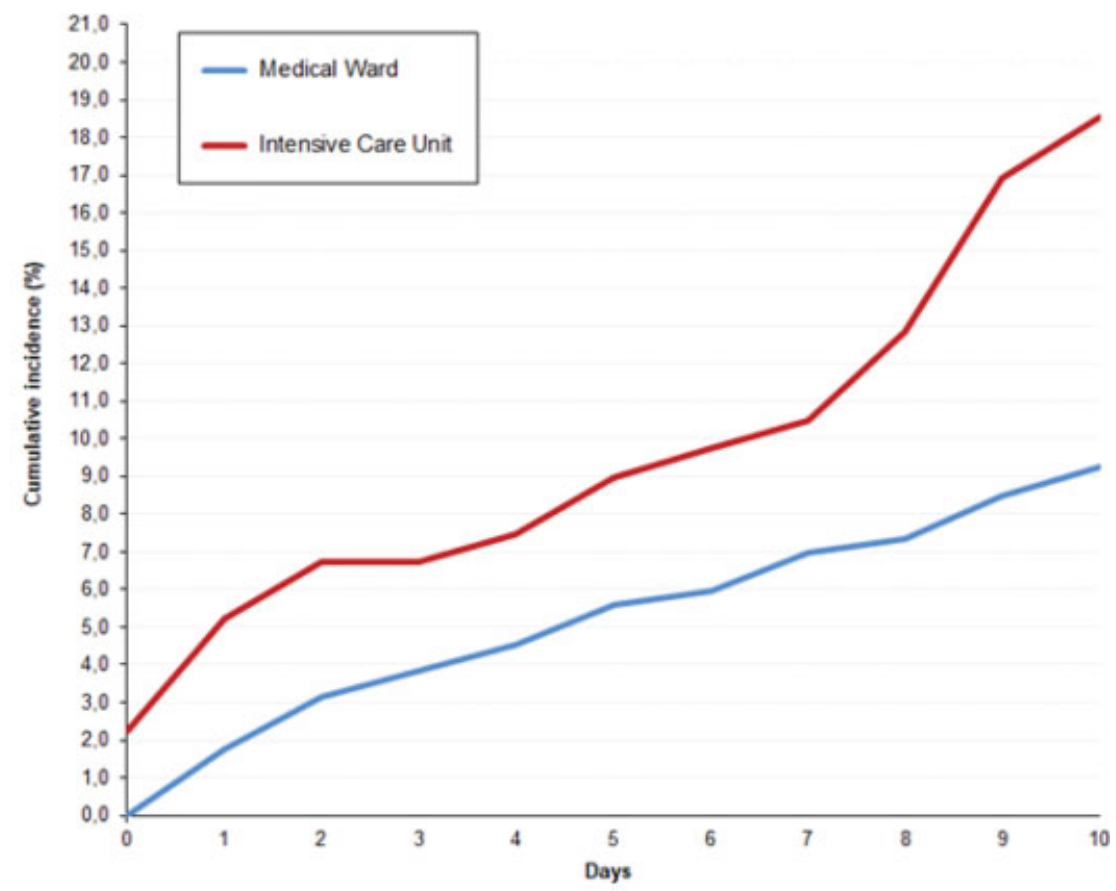

\begin{tabular}{|c|l|c|c|c|}
\hline \multicolumn{2}{|c|}{ Days } & $\mathbf{0}$ & $\mathbf{5}$ & $\mathbf{1 0}$ \\
\hline \multirow{2}{*}{ Patient at risk } & Ward & 286 & 286 & 260 \\
\cline { 2 - 5 } & ICU & 134 & 134 & 118 \\
\hline \multirow{2}{*}{ Deaths } & Ward & 0 & $16(5.59 \%)$ & $25(9.27 \%)$ \\
\cline { 2 - 5 } & ICU & $3(2.24 \%)$ & $12(8.98 \%)$ & $23(18.5 \%)$ \\
\hline
\end{tabular}

Fig. 4 Cumulative incidence of mortality in patients diagnosed with acute VTE during hospitalization for COVID-19 according to the disposition status: medical ward vs. ICU. COVID-19: coronavirus disease 2019; ICU: intensive care unit; VTE: venous thromboembolism 
to identify the optimal strategies for VTE prevention and diagnosis, and to mitigate the outcomes once VTE occurs.

\section{Appendix 1}

Coordinator of the RIETE Registry: Manuel Monreal.

RIETE Steering Committee Members: Paolo Prandoni,

Benjamin Brenner, and Dominique Farge-Bancel.

RIETE National Coordinators: Raquel Barba (Spain), Pierpaolo Di Micco (Italy), Laurent Bertoletti (France), Sebastian Schellong (Germany), Inna Tzoran (Israel), Abilio Reis (Portugal), Marijan Bosevski (R. Macedonia), Henri Bounameaux (Switzerland), Radovan Malý (Czech Republic), Peter Verhamme (Belgium), Joseph A. Caprini (United States), and Hanh My Bui (Vietnam).

RIETE Registry Coordinating Center: S\&H Medical Science Service.

\section{Members of the RIETE Group}

SPAIN: Adarraga MD, Agud M, Aibar J, Aibar MA, Amado C, Arcelus JI, Baeza C, Ballaz A, Barba R, Barbagelata C, Barrón M, Barrón-Andrés B, Blanco-Molina A, Botella E, Camon AM, Cañas I, Casado I, Castro J, Chasco L, Criado J, de Ancos C, de Miguel J, del Toro J, de la Torre MA, Demelo-Rodríguez P, DíazPedroche C, Díaz-Peromingo JA, Di Campli MV, Díez-Sierra J, Domínguez IM, Escribano JC, Falgá C, Farfán-Sedano AI, Fernández de Roitegui K, Fernández-Capitán $\mathrm{C}$, FernándezReyes JL, Fidalgo MA, Flores K, Font C, Font L, Francisco I, Furest I, Gabara C, Galeano-Valle F, García MA, García-Bragado F, García de Herreros M, García-Hernáez R, GarcíaMullor MM, García-Raso A, Gavín-Sebastián O, Gil-Díaz A, Gómez-Cuervo C, González-Martínez J, González-Olmedo J, Grau E, Giménez-Suau M, Guirado L, Gutiérrez J, HernándezBlasco L, Hernando E, Herreros M, Jara-Palomares L, Jaras MJ, Jiménez D, Jiménez R, Joya MD, Jou I, Lecumberri R, Lima J, Llamas P, Lobo JL, López-Jiménez L, López-Miguel P, LópezNúñez JJ, López-Reyes R, López-Sáez JB, Lorenzo A, Loring M, Madridano O, Maestre A, Marchena PJ, Martín del Pozo M, Martín-Martos F, Mella C, Mellado M, Mercado MI, Moisés J, Monreal M, Morales MV, Muñoz-Blanco A, Muñoz-Rivas N, Nieto JA, Núñez-Ares A, Núñez-Fernández MJ, Obispo B, Olid M, Olivares MC, Olivera PE, Orcastegui JL, Ortega-Recio MD, Osorio J, Otalora S, Otero R, Paredes D, Parra P, Parra V, Pedrajas JM, Pellejero G, Pérez-Jacoiste A, Porras JA, Portillo J, Riera-Mestre A, Rivas A, Rivera F, Rodríguez-Cobo A, Rodríguez-Matute C, Rogado J, Rosa V, Ruiz-Artacho P, RuizGiménez N, Ruiz-Ruiz J, Ruiz-Sada P, Sahuquillo JC, Salgueiro G, Sampériz A, Sánchez-Martínez R, Sánchez-Muñoz-Torrero JF, Sancho T, Sigüenza P, Soler S, Suriñach JM, Torres MI, Tolosa C, Trujillo-Santos J, Uresandi F, Valero B, Valle R, Vela JR, Vidal G, Villares P, Zamora C; ARGENTINA: Gutiérrez P, Vázquez FJ; BELGIUM: Vanassche T, Vandenbriele C, Verhamme P; CZECH REPUBLIC: Hirmerova J, Malý R; FRANCE: Benzidia I, Bertoletti L, Bura-Riviere A, Catella J, Crichi B, Debourdeau P, Espitia O, Farge-Bancel D, Helfer H, Mahé I, Moustafa F, Poenou G, Sanchez O; GERMANY: Schellong S; ISRAEL: Braester A, Brenner B, Tzoran I; ITALY: Bilora F, Bucherini E, Ciammaichella M, Colaizzo D, Di Micco P, Grand- one E, Mastroiacovo D, Maida R, Pace F, Pesavento R, Prandoni P, Quintavalla R, Rocci A, Siniscalchi C, Tufano A, Villalta S, Visonà $A$, Zalunardo B; LATVIA: Skride A; PORTUGAL: Ferreira $\mathrm{M}$, Fonseca $\mathrm{S}$, Martins $\mathrm{F}$, Meireles J; REPUBLIC OF MACEDONIA: Bosevski M; SWITZERLAND: Bounameaux $\mathrm{H}$, Mazzolai L; UNITED STATES: Bikdeli B, Caprini JA, Tafur AJ, Weinberg I, Wilkins H; VIETNAM: Bui HM.

\section{Funding}

This study was supported by Sanofi Spain with an unrestricted educational grant. The funders had no role in the design, conduct, or analyses, or the decision to submit this study.

\section{Conflict of Interest}

B.B. reports that he is a consulting expert, on behalf of the plaintiff, for litigation related to a specific type of inferior vena cava filters. All other authors have not reported any conflict of interest.

\section{Acknowledgments}

We express our gratitude to Sanofi Spain for supporting this registry with an unrestricted educational grant. We also thank the RIETE Registry Coordinating Center and S\&H Medical Science Service for their quality control data and logistic and administrative support, and Prof. Salvador Ortiz, Universidad Autónoma Madrid, and Silvia Galindo, both Statistical Advisors in S\&H Medical Science Service, for the statistical analysis of the data presented in this article.

\section{References}

1 Bikdeli B, Madhavan MV, Jimenez DGlobal COVID-19 Thrombosis Collaborative Group, Endorsed by the ISTH, NATF, ESVM, and the IUA, Supported by the ESC Working Group on Pulmonary Circulation and Right Ventricular Function. et al;. COVID-19 and thrombotic or thromboembolic disease: Implications for prevention, antithrombotic therapy, and follow-up. J Am Coll Cardiol 2020;75(23):2950-2973

2 Driggin E, Madhavan MV, Bikdeli B, et al. Cardiovascular considerations for patients, health care workers, and health systems during the coronavirus disease 2019 (COVID-19) pandemic. J Am Coll Cardiol 2020;75(18):2352-2371

3 Helms J, Tacquard C, Severac FCRICS TRIGGERSEP Group (Clinical Research in Intensive Care and Sepsis Trial Group for Global Evaluation and Research in Sepsis)., et al; . High risk of thrombosis in patients with severe SARS-CoV-2 infection: a multicenter prospective cohort study. Intensive Care Med 2020;46(06):1089-1098

4 Lodigiani C, Iapichino G, Carenzo LHumanitas COVID-19 Task Force. , et al. Venous and arterial thromboembolic complications in COVID-19 patients admitted to an academic hospital in Milan, Italy. Thromb Res 2020;191:9-14

5 Cui S, Chen S, Li X, Liu S, Wang F. Prevalence of venous thromboembolism in patients with severe novel coronavirus pneumonia. J Thromb Haemost 2020;18(06):1421-1424

6 Klok FA, Kruip MJHA, van der Meer NJM, et al. Confirmation of the high cumulative incidence of thrombotic complications in critically ill ICU patients with COVID-19: an updated analysis. Thromb Res 2020;191:148-150

7 Llitjos JF, Leclerc M, Chochois C, et al. High incidence of venous thromboembolic events in anticoagulated severe COVID-19 patients. J Thromb Haemost 2020;18(07):1743-1746 
8 Jiménez D, Bikdeli B, Quezada ARIETE investigators. et al. Hospital volume and outcomes for acute pulmonary embolism: multinational population based cohort study. BMJ 2019;366: 14416

9 Trujillo-Santos J, Nieto JA, Tiberio GRIETE Registry. et al. Predicting recurrences or major bleeding in cancer patients with venous thromboembolism. Findings from the RIETE Registry. Thromb Haemost 2008;100(03):435-439

10 Laporte S, Mismetti P, Décousus HRIETE Investigators. et al. Clinical predictors for fatal pulmonary embolism in 15,520 patients with venous thromboembolism: findings from the Registro Informatizado de la Enfermedad TromboEmbolica venosa (RIETE) Registry. Circulation 2008;117(13):1711-1716

11 Bikdeli B, Jimenez D, Hawkins MRIETE Investigators. et al. Rationale, design and methodology of the computerized registry of patients with venous thromboembolism (RIETE). Thromb Haemost 2018;118(01):214-224

12 Prandoni P, Cogo A, Bernardi E, et al. A simple ultrasound approach for detection of recurrent proximal-vein thrombosis. Circulation 1993;88(4, Pt 1):1730-1735

13 Guan WJ, Ni ZY, Hu YChina Medical Treatment Expert Group for Covid-19. , et al. Clinical characteristics of coronavirus disease 2019 in China. N Engl J Med 2020;382(18):1708-1720

14 Richardson S, Hirsch JS, Narasimhan Mand the Northwell COVID19 Research Consortium., et al. Presenting characteristics, comorbidities, and outcomes among 5700 patients hospitalized with COVID-19 in the New York City area. JAMA 2020;323(20): 2052-2059

15 Wang D, Hu B, Hu C, et al. Clinical characteristics of 138 hospitalized patients with 2019 novel coronavirus-infected pneumonia in Wuhan, China. JAMA 2020;323:1061-1069

16 Yang X, Yu Y, Xu J, et al. Clinical course and outcomes of critically ill patients with SARS-CoV-2 pneumonia in Wuhan, China: a single-centered, retrospective, observational study. Lancet Respir Med 2020;8(05):475-481

17 Mehra MR, Desai SS, Kuy S, Henry TD, Patel AN. Cardiovascular disease, drug therapy, and mortality in Covid-19. N Engl J Med 2020;382(25):e102

18 Jiménez D, de Miguel-Díez J, Guijarro RRIETE Investigators. , et al. Trends in the management and outcomes of acute pulmonary embolism. J Am Coll Cardiol 2016;67(02):162-170

19 Wu Z, McGoogan JM. Characteristics of and important lessons from the Coronavirus Disease 2019 (COVID-19) outbreak in
China: summary of a report of 72314 cases from the Chinese Center for Disease Control and Prevention. JAMA 2020;323(13): 1239-1242

20 Grasselli G, Zangrillo A, Zanella ACOVID-19 Lombardy ICU Network. et al. Baseline characteristics and outcomes of 1591 patients infected with SARS-CoV-2 admitted to ICUs of the Lombardy region, Italy. JAMA 2020;323:1574-1581

21 Wang T, Chen R, Liu C, et al. Attention should be paid to venous thromboembolism prophylaxis in the management of COVID-19. Lancet Haematol 2020;7(05):e362-e363

22 Tang N, Bai H, Chen X, Gong J, Li D, Sun Z. Anticoagulant treatment is associated with decreased mortality in severe coronavirus disease 2019 patients with coagulopathy. J Thromb Haemost 2020;18(05):1094-1099

23 Cattaneo M, Bertinato EM, Birocchi S, et al. Pulmonary embolism or pulmonary thrombosis in COVID-19? Is the recommendation to use high-dose heparin for thromboprophylaxis justified? Thromb Haemost 2020;120(08):1230-1232

24 Ackermann M, Verleden SE, Kuehnel M, et al. Pulmonary vascular endothelialitis, thrombosis, and angiogenesis in Covid-19. N Engl J Med 2020;383(02):120-128

25 Lax SF, Skok K, Zechner P, et al. Pulmonary arterial thrombosis in COVID-19 with fatal outcome: results from a prospective, singlecenter, clinicopathologic case series. Ann Intern Med 2020;173 (05):350-361

26 Thachil J, Srivastava A. SARS-2 coronavirus-associated hemostatic lung abnormality in COVID-19: is it pulmonary thrombosis or pulmonary embolism? Semin Thromb Hemost 2020;46(07): 777-780

27 Zhou F, Yu T, Du R, et al. Clinical course and risk factors for mortality of adult inpatients with COVID-19 in Wuhan, China: a retrospective cohort study. Lancet 2020;395(10229): 1054-1062

28 Arentz M, Yim E, Klaff L, et al. Characteristics and outcomes of 21 critically ill patients with COVID-19 in Washington State. JAMA 2020;323(16):1612-1614

29 Bhatraju PK, Ghassemieh BJ, Nichols M, et al. Covid-19 in critically ill patients in the Seattle region - case series. N Engl J Med 2020; 382(21):2012-2022

30 Wichmann D, Sperhake JP, Lütgehetmann M, et al. Autopsy findings and venous thromboembolism in patients with COVID19. A prospective cohort study. Ann Intern Med 2020;173(04): 268-277 